\title{
Recombination processes in passivated boron-implanted black silicon emitters
}

Guillaume von Gastrow, Pablo Ortega, Ramon Alcubilla, Sebastian Husein, Tara Nietzold, Mariana Bertoni, and Hele Savin

Citation: Journal of Applied Physics 121, 185706 (2017); doi: 10.1063/1.4983297

View online: http://dx.doi.org/10.1063/1.4983297

View Table of Contents: http://aip.scitation.org/toc/jap/121/18

Published by the American Institute of Physics

\section{Articles you may be interested in}

Determining interface properties limiting open-circuit voltage in heterojunction solar cells

Journal of Applied Physics 121, 185301 (2017); 10.1063/1.4982752

Light-induced activation and deactivation of bulk defects in boron-doped float-zone silicon

Journal of Applied Physics 121, 185702 (2017); 10.1063/1.4983024

Coexistence of strongly and weakly confined energy levels in $(\mathrm{Cd}, \mathrm{Zn})$ Se quantum dots: Tailoring the near-bandedge and defect-levels for white light emission

Journal of Applied Physics 121, 183102 (2017); 10.1063/1.4983094

Modeling of light-induced degradation due to Cu precipitation in p-type silicon. I. General theory of precipitation under carrier injection

Journal of Applied Physics 121, 195703 (2017); 10.1063/1.4983454

Further insight on recombination losses in the intrinsic layer of a-Si:H solar cells using computer modeling tools Journal of Applied Physics 121, 184502 (2017); 10.1063/1.4983010

Size-dependent persistent photocurrent and its origin in dc sputtered indium oxide films under UV and sub-band gap illuminations

Journal of Applied Physics 121, 185303 (2017); 10.1063/1.4983077

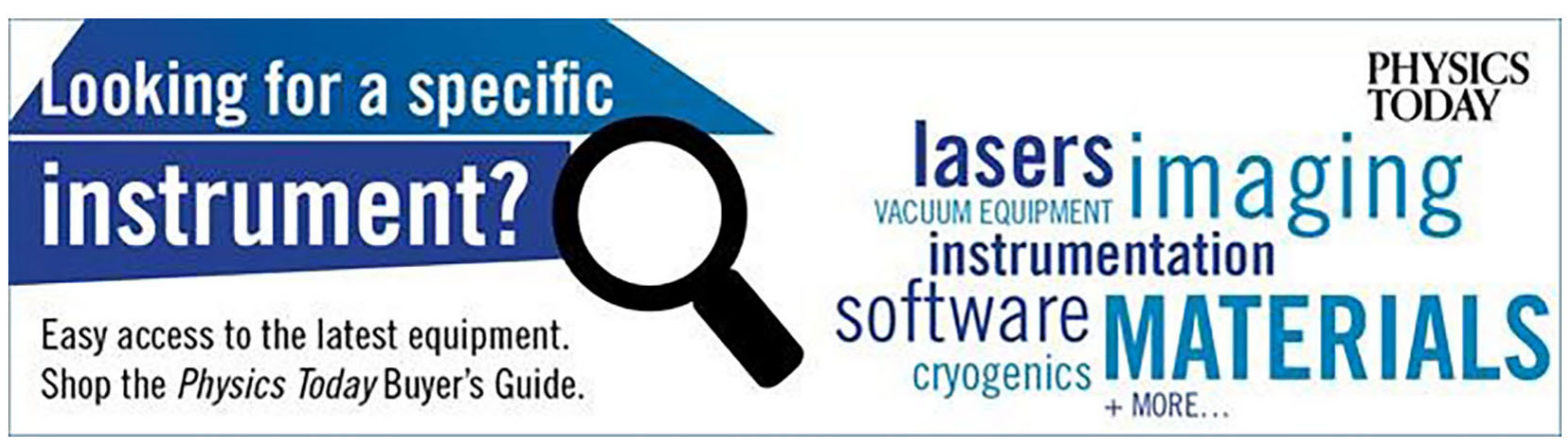




\title{
Recombination processes in passivated boron-implanted black silicon emitters
}

\author{
Guillaume von Gastrow, ${ }^{1, a)}$ Pablo Ortega, ${ }^{2}$ Ramon Alcubilla, ${ }^{2}$ Sebastian Husein, ${ }^{3}$ \\ Tara Nietzold, ${ }^{3}$ Mariana Bertoni, ${ }^{3}$ and Hele Savin ${ }^{1}$ \\ ${ }^{1}$ Aalto University, Department of Electronics and Nanoengineering, Tietotie 3, 02150 Espoo, Finland \\ ${ }^{2}$ Universitat Politècnica de Catalunya, Dept. Enginyeria Electrònica, C/ Jordi Girona 1-3, Mòdul C4, \\ E - 08034 Barcelona, Spain \\ ${ }^{3}$ Defect Lab, Ira A. Fulton Schools of Engineering, School of Electrical, Computer and Energy Engineering \\ (ECEE), Arizona State University, 551 E. Tylor Mall, Tempe, Arizona 85287, USA
}

(Received 19 January 2017; accepted 28 April 2017; published online 11 May 2017)

\begin{abstract}
In this paper, we study the recombination mechanisms in ion-implanted black silicon (bSi) emitters and discuss their advantages over diffused emitters. In the case of diffusion, the large bSi surface area increases emitter doping and consequently Auger recombination compared to a planar surface. The total doping dose is on the contrary independent of the surface area in implanted emitters, and as a result, we show that ion implantation allows control of emitter doping without compromise in the surface aspect ratio. The possibility to control surface doping via implantation anneal becomes highly advantageous in bSi emitters, where surface passivation becomes critical due to the increased surface area. We extract fundamental surface recombination velocities $S_{n}$ through numerical simulations and obtain the lowest values at the highest anneal temperatures. With these conditions, an excellent emitter saturation current $\left(\mathrm{J}_{0 \mathrm{e}}\right)$ is obtained in implanted bSi emitters, reaching $20 \mathrm{fA} / \mathrm{cm}^{2} \pm 5 \mathrm{fA} / \mathrm{cm}^{2}$ at a sheet resistance of $170 \Omega / \mathrm{sq}$. Finally, we identify the different regimes of recombination in planar and $\mathrm{bSi}$ emitters as a function of implantation anneal temperature. Based on experimental data and numerical simulations, we show that surface recombination can be reduced to a negligible contribution in implanted bSi emitters, which explains the low $\mathrm{J}_{0 \mathrm{e}}$ obtained. Published by AIP Publishing. [http://dx.doi.org/10.1063/1.4983297]
\end{abstract}

\section{INTRODUCTION}

A promising process for high-efficiency solar cells, surface nanostructuring (black silicon or $\mathrm{bSi}$ ), can provide exceptional benefits in terms of light absorption. ${ }^{1}$ While surface recombination has limited bSi electrical performance for years, advances in passivation-and especially the use of atomic layer deposition (ALD) - have made it possible to obtain low surface recombination velocities in such high aspect ratio surfaces. ${ }^{2-5}$ Consequently, research on bSi emitters has been steadily expanding in the past few years, ${ }^{6-10}$ and ALD has also demonstrated effective passivation of both phosphorus ${ }^{11}$ and boron bSi emitters. ${ }^{12,13}$ However, most of the research involving textured emitters has been limited to emitter doping via diffusion, although a number of studies point out the necessity of a compromise in the bSi dimensions in order to limit emitter recombination. ${ }^{6,714-17}$ In fact, excessive diffusion through the bSi increased surface area causes higher Auger recombination than in planar surfaces. ${ }^{10,18}$ This phenomenon has been reported to result in high emitter saturation current $\left(\mathrm{J}_{0 \mathrm{e}}\right)$ and/or in the poor blue response of nanostructured solar cells that integrate emitter on the front side (for instance, PERC and Al-BSF cells). ${ }^{6,10,14-16}$ This issue can be prevented with the help of case-specific approaches. Oh et al. identified the doping ranges at which the Auger mechanism dominates over surface recombination, showing that

\footnotetext{
${ }^{\text {a) }}$ Author to whom correspondence should be addressed: guillaume.von. gastrow@aalto.fi. Tel.: +358 504318869 .
}

diffusion parameters should be carefully adapted to bSi structures. ${ }^{19}$ However, further etching had to be performed to decrease bSi doping in their final solar cell, which altered the antireflection properties and the sheet resistance. Kafle et al. optimized emitter performance by decreasing the bSi aspect ratio and by reducing the amount of diffused dopant in the structures,${ }^{10}$ which also resulted in a tradeoff in reflectance.

Here, we study the possibility to form high quality $\mathrm{bSi}$ emitters by boron implantation. We employ $\mathrm{ALD} \mathrm{Al}_{2} \mathrm{O}_{3}$ passivation, which allows efficient surface passivation of highly doped p-type emitters. ${ }^{20,21}$ We discuss the possibility to solve the common issues encountered with emitter diffusion and analyze the recombination process in implanted emitters. Although few studies exist on ion-implanted textured sili$\mathrm{con}^{22,23}$ and to our knowledge none on $\mathrm{bSi}$, ion implantation can provide a number of advantages in comparison to diffusion. It may allow controlling recombination in bSi without tradeoff in dimensions, since the total impurity dose injected in the nanostructures is fixed regardless of surface area. It also provides higher uniformity and reproducibility, ${ }^{24}$ reduces the number of processing steps by avoiding formation of dopant glass at the silicon surface, and finally, facilitates the formation of selective emitters. ${ }^{25}$ Thus, the first part of this paper compares sheet resistance and reflectance in implanted and diffused emitters. In the second part, the same emitters are compared in terms of emitter saturation current performance and of recombination mechanisms. The respective effect of surface and Auger recombination mechanisms is discussed for both doping techniques. Finally, in the third 
TABLE I. Estimated $\mathrm{SiO}_{2}$ thicknesses corresponding to each implantation anneal temperature.

\begin{tabular}{lc}
\hline \hline Implantation anneal temperature $\left({ }^{\circ} \mathrm{C}\right)$ & Estimated $\mathrm{SiO}_{2}$ thickness $(\mathrm{nm})$ \\
\hline 850 & $\mathrm{~N} / \mathrm{A}$ \\
950 & $6 \pm 1$ \\
1000 & $8 \pm 2$ \\
1050 & $12 \pm 1$ \\
\hline \hline
\end{tabular}

part, electron surface recombination velocities are extracted based on experimental data and numerical simulations, which allows determination of the limiting recombination mechanism in bSi implanted emitters.

\section{EXPERIMENTAL DETAILS}

This study was realized on magnetically cast Czochralski phosphorus-doped silicon wafers with (100) orientation and a resistivity of $3.4 \pm 0.2 \Omega \cdot \mathrm{cm}$. The oxygen concentration was $6.0-10.0$ ppma and the wafer thickness $445 \pm 5 \mu \mathrm{m}$. All samples were processed identically on both sides to obtain symmetrical samples needed for emitter saturation current $\left(\mathrm{J}_{0 \mathrm{e}}\right)$ measurements. Black silicon was prepared by inductively coupled plasma reactive ion etching in an Oxford Instruments Plasmalab System 100-ICP 180 device. The etching was performed using a $\mathrm{SF}_{6} / \mathrm{O}_{2}$ plasma at a temperature of $-120^{\circ} \mathrm{C}$ and at a pressure of $10 \mathrm{mTorr}$. After bSi etching, the wafers were separated into two groups for diffusion and implantation. Boron implantation was performed at an energy of $10 \mathrm{keV}$, typically used in the photovoltaics industry to limit damage formation, ${ }^{26}$ and with a dose of $3 \times 10^{15} \mathrm{~cm}^{-2}$, which ensures that implantation damage can be cured in a range of anneal temperatures from $950{ }^{\circ} \mathrm{C}$ to $1050^{\circ} \mathrm{C}^{27}$ The ion beam tilt was kept to the standard value of $7^{\circ 28}$ as a tradeoff between damage formation and beam screening by the bSi needles. ${ }^{29}$ After implantation, a $20 \mathrm{~min}$ anneal was performed in the nitrogen ambient at temperatures ranging from $850^{\circ} \mathrm{C}$ to $1050^{\circ} \mathrm{C}$ (Table I), followed by oxidation for $20 \mathrm{~min}$ at the same temperature and by a $5 \mathrm{~min}$ anneal in nitrogen to anneal the silicon oxide.

Similarly, boron diffusions were performed at different temperatures $\left(825^{\circ} \mathrm{C}, 875^{\circ} \mathrm{C}, 925^{\circ} \mathrm{C}\right.$, and $\left.975^{\circ} \mathrm{C}\right)$. Doping was performed using a solid boron source in the $\mathrm{N}_{2}$ ambient for $45 \mathrm{~min}$ followed by a $5 \% \mathrm{HF}$ dip for $2 \mathrm{~min}$. Next, the diffused samples underwent a low thermal oxidation (LTO step) in pure $\mathrm{O}_{2}$ atmosphere at $650^{\circ} \mathrm{C}$ for $30 \mathrm{~min}$ and another $5 \%$ HF dip for $2 \mathrm{~min}$ in order to etch the boron rich layer. In addition, planar reference wafers were doped by implantation and diffusion using the same parameters.

The surface of the implanted emitters was passivated using different dielectric layers listed in Table II. Thermal $\mathrm{SiO}_{2}$ was grown during implantation anneal, and $20 \mathrm{~nm}$ of $\mathrm{Al}_{2} \mathrm{O}_{3}$ was deposited by thermal atomic layer deposition (ALD) at $200^{\circ} \mathrm{C}$ from trimethylaluminium and a combination of water and ozone at a concentration of $162 \mathrm{~g} / \mathrm{m}^{3} .{ }^{30}$ The thermal oxide was removed in sample SRV4 in a BHF solution before ALD. In samples SRV1 and SRV3, $\mathrm{Al}_{2} \mathrm{O}_{3}$ was grown directly on top of thermal $\mathrm{SiO}_{2}$. The $\mathrm{Al}_{2} \mathrm{O}_{3}$ passivation was activated by annealing at $425^{\circ} \mathrm{C}$ for $30 \mathrm{~min}$ in $\mathrm{N}_{2}$ and the term "as deposited" refers to non-annealed $\mathrm{Al}_{2} \mathrm{O}_{3}$ samples. The diffused emitters were passivated only with $\mathrm{Al}_{2} \mathrm{O}_{3}$ films, deposited and annealed in the same conditions as reported above.

The oxide thickness was measured by ellipsometry and supplemented by capacitance values extracted with the corona oxide characterization of semiconductor (COCOS) technique. ${ }^{31}$ COCOS was also used to extract the interface fixed charge in the films. Sheet resistance was measured in all samples with a four-point probe ${ }^{32}$ and verified with the Sinton WCT-120 apparatus (conductance technique). ${ }^{33}$ Despite the lack of knowledge on the current distribution inside bSi needles when it is injected through metal probes, the four-point probe results are usually consistent with the values measured from the dark conductance. ${ }^{10,22,23}$ The Sinton tool was also used for minority carrier lifetime and $\mathrm{J}_{0 \mathrm{e}}$ measurements. The $\mathrm{J}_{0 \mathrm{e}}$ was extracted at $298 \mathrm{~K}$ from the injection level-dependent carrier lifetime curve, based on the method originally developed by Kane and Swanson, ${ }^{34}$ which was later improved by Blum et al. and is now used in WCT$120 .{ }^{35}$ Note that $\mathrm{J}_{0 \mathrm{e}}$ tends to be underestimated with the models previously implemented. ${ }^{35}$ Contrarily to other studies, ${ }^{23,36}$ no $\mathrm{J}_{0 \mathrm{e}}$ rescaling based on the surface area was performed in the bSi results, because the effective value is more relevant from the solar cell point of view. The $\mathrm{J}_{0 \mathrm{e}}$ was averaged over the values extracted at $\pm 30 \%$ of the specified minority carrier excess density (SMCD) taken as $\Delta n \approx 10 N_{D}$ with $\mathrm{N}_{\mathrm{D}}$ the bulk doping. Note that the SMCD was however limited by the maximum achievable injection level, which depends on the minority carrier lifetime. The $\mathrm{J}_{\mathrm{Oe}}$ extraction is based on the intrinsic lifetime parametrization by Richter et $a l^{37}$ and on the band gap narrowing model from Schenk. ${ }^{38}$ In addition, corrections can be performed employing finite diffusion coefficients, ${ }^{39}$ but they become critical only for very low lifetime values. In this work, neglecting

TABLE II. Passivation layers employed with implanted emitters. The $\mathrm{SiO}_{2}$ layer thickness depends on the implantation anneal temperature and is reported for each temperature in Table I. Passivation results and dielectric charge values are reported after oxidation at $1050{ }^{\circ} \mathrm{C}\left(950^{\circ} \mathrm{C}\right.$ in the case of SRV2 charge). The same n-type substrates as in the rest of the study were used without additional doping step.

\begin{tabular}{lccc}
\hline \hline Passivation name & Dielectric layer(s) & Dielectric charge $\left(\mathrm{cm}^{-2}\right)$ & $\begin{array}{r}\text { Maximum surface recombination } \\
\text { velocity at } 10^{15} \mathrm{~cm}^{-3}(\mathrm{~cm} / \mathrm{s})\end{array}$ \\
\hline SRV1 & $\mathrm{SiO}_{2}+$ As deposited $\mathrm{Al}_{2} \mathrm{O}_{3}$ & $-(6.1 \pm 0.2) \times 10^{11}$ & 165 \\
$\mathrm{SRV} 2$ & $\mathrm{SiO}_{2}$ & $+(1.4 \pm 0.1) \times 10^{11}$ & 96 \\
$\mathrm{SRV3}$ & $\mathrm{SiO}_{2}+$ annealed $\mathrm{Al}_{2} \mathrm{O}_{3}$ & $-(7.2 \pm 0.1) \times 10^{11}$ & 48 \\
$\mathrm{SRV4}$ & Annealed $\mathrm{Al}_{2} \mathrm{O}_{3}$ & $-(2.5 \pm 0.1) \times 10^{12}$ & 6 \\
\hline \hline
\end{tabular}


finite diffusion coefficients may lead to $\mathrm{J}_{0 \mathrm{e}}$ underestimation in the poor quality emitters, e.g., those annealed at $850^{\circ} \mathrm{C}$. Apart from this error source, a large uncertainty in the extracted $\mathrm{J}_{0 \mathrm{e}}$ can arise from its dependence on the minority carrier excess density. ${ }^{23}$ The error bars in the graphs thus indicate the $\mathrm{J}_{0 \mathrm{e}}$ variation in the range $\Delta n=\operatorname{SMCD}(1 \pm 30 \%)$. Note that some of the error bars are included within the symbols.

\section{EXPERIMENTAL RESULTS ON DIFFUSED AND IMPLANTED EMITTERS}

\section{A. Sheet resistance, doping, and reflectance}

This section presents sheet resistance and doping results, which are needed to assess the $\mathrm{J}_{0 \mathrm{e}}$ performance. Reflectance curves will be used to discuss the impact of the doping processes on the optical properties of $\mathrm{bSi}$.

Figure 1 shows the measured sheet resistance as a function of implantation or diffusion temperature in both black silicon and planar samples. Implanted and diffused emitters differ by the nature of the doping dose. As implantation dose is fixed, sheet resistance should not vary as a function of temperature once all boron atoms have been activated, given the limited variation of mobilities in the doping range of $10^{18} \mathrm{~cm}^{-3}$ to $10^{20} \mathrm{~cm}^{-3}$ considered here. ${ }^{40}$ On the contrary, the boron source is virtually infinite in the case of diffused emitters, and consequently, the boron concentration in silicon is in this case determined by temperature. Figure 1(a) shows that, in implanted emitters, sheet resistance saturates at temperatures of $950{ }^{\circ} \mathrm{C}$ and beyond, reaching a value of approximately $170 \Omega /$ sq in bSi. Consequently, an anneal temperature of at least $950^{\circ} \mathrm{C}$ is necessary to activate all boron atoms, which is consistent with the results reported by Müller et al. at the same implantation dose. ${ }^{27}$ Figure 1(b) shows that, as expected in diffused emitters, sheet resistance decreases down to $20 \Omega / \mathrm{sq}$ in bSi when the temperature is increased to $975^{\circ} \mathrm{C}$. In addition, Fig. 1 highlights an interesting difference between implanted and diffused emitters. With identical process parameters, the sheet resistance of implanted emitters appears higher in bSi than in planar surfaces, while the opposite trend is observed in diffused emitters. Although it remains unclear whether bSi sheet resistance is directly comparable to the planar values due to the difference in current path, this observation may originate from the difference of geometry between bSi and planar surfaces. In diffused emitters, boron is able to penetrate from the sides of the bSi needles, thus increasing the total boron content in comparison with a planar surface. On the other hand, the local dose in implanted bSi structures is lower than the target dose because a fixed amount of boron is implanted. This may explain the high sheet resistance values measured compared to planar references. A similar reduction of effective dose was also suggested in a previous work on implanted pyramid-textured silicon. ${ }^{29}$

The doping profiles measured in planar emitters using the electrochemical capacitance-voltage (ECV) method are shown in Fig. 2. The surface doping, which can significantly affect boron and phosphorus emitter surface passivation, ${ }^{23,41}$ decreases in implanter emitters from $(4.5 \pm 0.1) \times 10^{19} \mathrm{~cm}^{-3}$ to $(1.90 \pm 0.07) \times 10^{19} \mathrm{~cm}^{-3}$ under the effect of increasing anneal temperature. In the same time, the emitter depth increases from $0.7 \mu \mathrm{m}$ to about $1.5 \mu \mathrm{m}$ [Fig. 2(a)]. In diffused emitters, surface doping increases from $4.5 \times 10^{19} \mathrm{~cm}^{-3}$ to $2.2 \times 10^{20} \mathrm{~cm}^{-3}$ at higher temperatures. Doping profiles generated using the process simulator ICECREM ${ }^{42}$ are plotted along the ECV profiles in Fig. 2(a); it appears that those profiles match well with the experimental ones.

The bSi structures used in this study, with a height of $450 \mathrm{~nm}$ and a base diameter of $200 \mathrm{~nm}$ in average, are shown in Fig. 3 and seem not to have been altered by solid source diffusion or by implantation and anneal. This is confirmed by the reflectance curves that demonstrate extremely low values in the wavelength range from UV to near infrared. Little difference is observed compared to the reference curve of base-doping bSi, as reported in a previous study on bSi doped using various diffusion processes. ${ }^{12}$ Thus, the slight difference between the reflectance curves should be attributed to measurement uncertainty rather than to a potential effect of the doping process.

\section{B. Surface passivation}

ALD $\mathrm{Al}_{2} \mathrm{O}_{3}$ is known to passivate well boron-doped emitters after post-anneal. ${ }^{43,44}$ Therefore, we focus first on this passivation layer and study the way it affects samples with various boron profiles. The emitter saturation current $\mathrm{J}_{0 \mathrm{e}}$, which is a common measure for surface passivation and
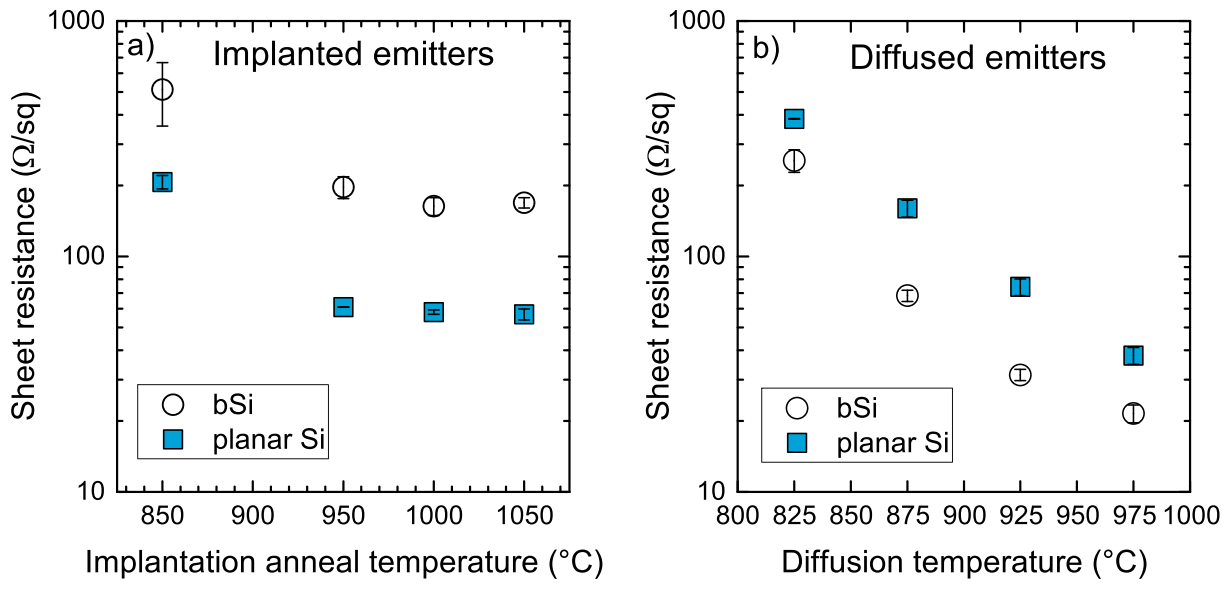

FIG. 1. Average sheet resistance values obtained from four-point probe and conductance measurements as a function of processing temperature. Results are shown for both planar and black silicon samples in (a) implanted emitters and (b) diffused emitters. Error bars indicate the standard deviation of four-point probe and of conductance measurements. 

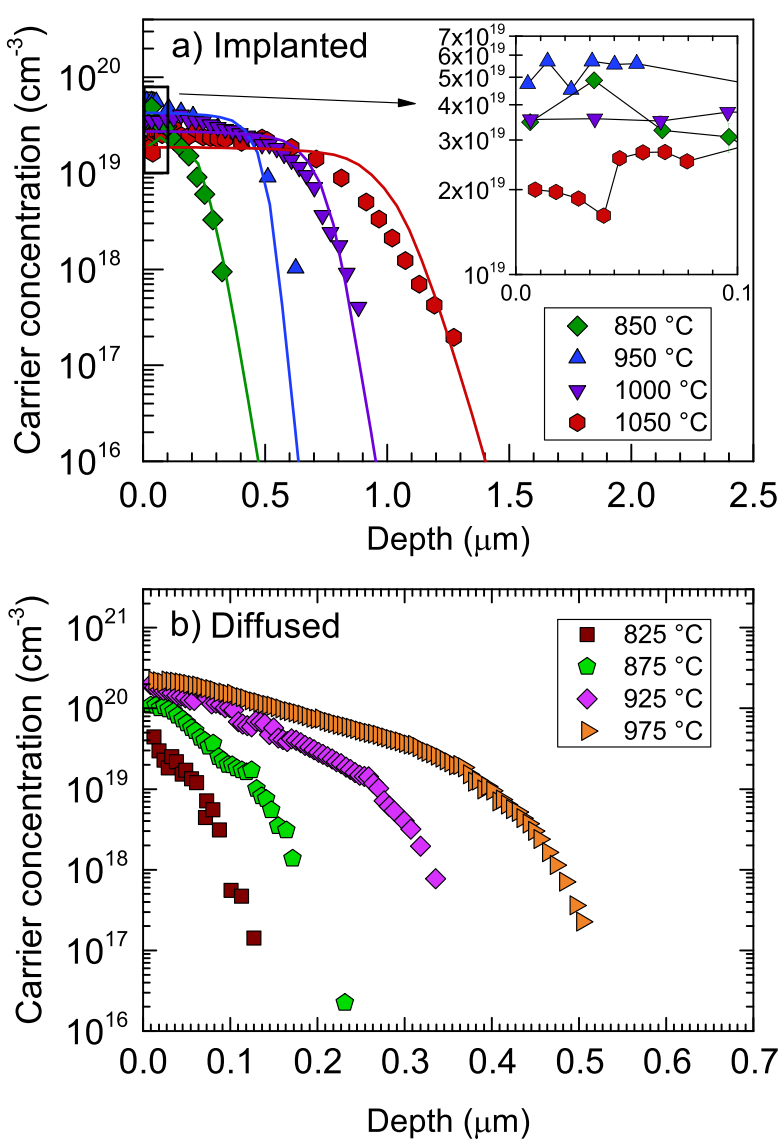

FIG. 2. Doping profiles measured by ECV (symbols) on (a) implanted and (b) diffused planar emitters. The implantation anneal or diffusion temperatures are indicated in the legend. The solid lines in (a) represent simulated dopant profiles obtained from the ICECREM software. The inset shows the surface doping values at each anneal temperature with solid lines as guides to the eye. Measurement uncertainties are included in the symbols.

emitter recombination, is plotted in Fig. 4. Figure 4(a) shows that the implanted emitter saturation current is systematically lower in bSi than in its planar counterpart, while it is systematically higher in diffused emitters. This is coherent with the

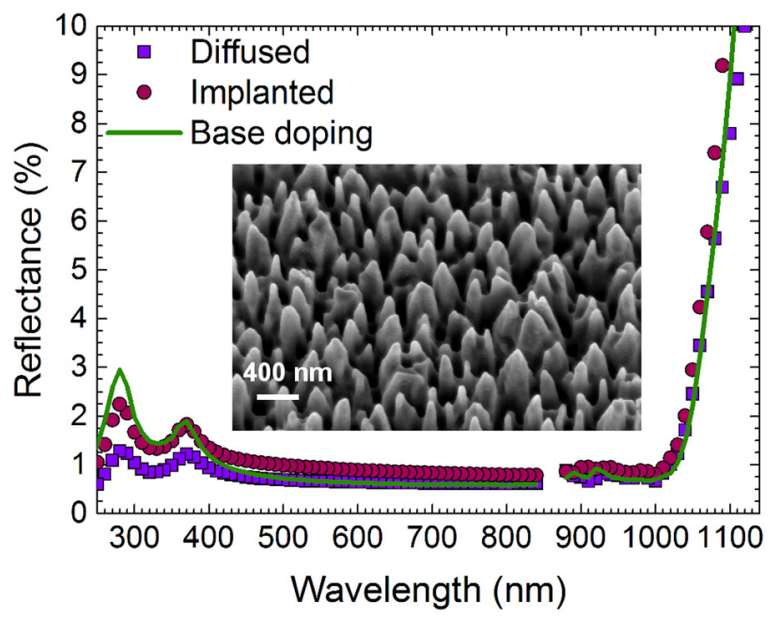

FIG. 3. Total reflectance of bSi emitters after diffusion at $925^{\circ} \mathrm{C}$, after implantation anneal at $850^{\circ} \mathrm{C}$, and bSi reference without additional doping step. The samples were coated with $20 \mathrm{~nm}$ of $\mathrm{Al}_{2} \mathrm{O}_{3}$. A SEM image of a bSi emitter after diffusion at $975^{\circ} \mathrm{C}$ is shown as an inset. The measurements points in the $850 \mathrm{~nm}$ region were artefacts caused by the change of detector and are not displayed in the graph.
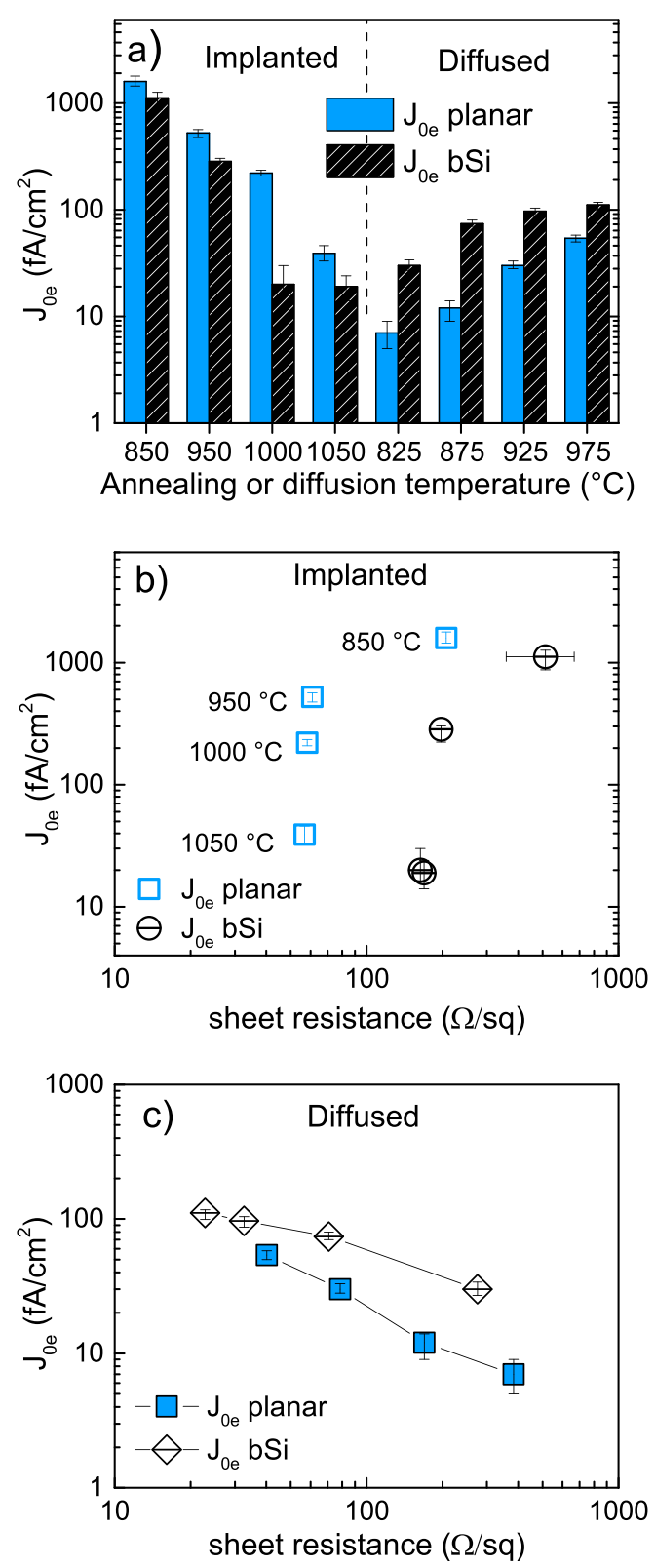

FIG. 4. Emitter saturation currents in $\mathrm{Al}_{2} \mathrm{O}_{3}$-passivated emitters after postdeposition anneal at $425^{\circ} \mathrm{C}$ for $30 \mathrm{~min}$ in $\mathrm{N}_{2}$ (passivation film SRV4): (a) Comparison of $\mathrm{J}_{0 \mathrm{e}}$ values measured in planar and $\mathrm{bSi}$ emitter processed by implantation or diffusion. (b) Measured $\mathrm{J}_{0 \mathrm{e}}$ as a function of sheet resistance in implanted emitters. The points were obtained at a different anneal temperatures increasing from top to bottom. (c) Experimental $\mathrm{J}_{0 \mathrm{e}}$ values as a function of sheet resistance in diffused emitters. Error bars indicate uncertainty in $\mathrm{J}_{\mathrm{Oe}}$ extraction caused by injection level-dependence or standard deviation of sheet resistance measurements.

trend observed in sheet resistances, assuming that they are comparable for bSi and planar emitters. Thus, it can be inferred that the high $\mathrm{J}_{0 \mathrm{e}}$ values in bSi diffused emitters, compared to the planar references, originate from high Auger recombination caused by increased doping.

While excellent $J_{0 e}$ values of $10 \mathrm{fA} / \mathrm{cm}^{2}$ can be obtained with boron diffusion on planar samples [Fig. 4(a)], the application to bSi surfaces is not straightforward and requires fine tuning of the experimental conditions to ensure sufficient emitter passivation. ${ }^{19}$ Indeed, in order to obtain low $\mathrm{J}_{0 \mathrm{e}}(30$ $\mathrm{fA} / \mathrm{cm}^{2}$ ) on diffused $\mathrm{bSi}$, significant reduction of the doping 
$\left(\mathrm{R}_{\text {sh }}\right.$ of $275 \Omega / \mathrm{sq}$ ) was required [Fig. 4(c)]. In implanted bSi emitters, on the contrary, it was possible to obtain a low $\mathrm{J}_{0 \mathrm{e}}$ of $20 \mathrm{fA} / \mathrm{cm}^{2}$ with a sheet resistance of $170 \Omega / \mathrm{sq}$.

Figure 4(b) focuses more specifically on the effect of implantation on $\mathrm{J}_{0 \mathrm{e}}$ and on sheet resistance. After anneal at $850^{\circ} \mathrm{C}$, the planar and $\mathrm{bSi}$ emitter saturation current is the highest most likely due to lattice defects and inactive boron remaining after implantation, as confirmed by the higher sheet resistance. The $\mathrm{J}_{0 \mathrm{e}}$ values then continuously improve under the influence of temperature increase. In fact, Müller et al. showed that a $10 \mathrm{~min}$ anneal at a temperature of $1050^{\circ} \mathrm{C}$ was needed to fully suppress Shockley-Read-Hall (SRH) recombination due to inactive boron and lattice defects. ${ }^{27,45}$ However, the relative impact of each recombination mechanism (Auger recombination, surface recombination, and emitter SRH recombination) on $\mathrm{J}_{0 \mathrm{e}}$ cannot be obtained from the results displayed in Fig. 4.

In order to study the impact of emitter Auger recombination on $\mathrm{J}_{0 \mathrm{e}}$, the surface passivation quality was varied with the help of different dielectric layers (Table II). The same ntype substrates without diffusion or implantation step were used. Maximum surface recombination velocities $S_{\text {eff,max }}$ (assuming infinite bulk lifetime) were calculated from measurements of lifetime $\tau_{\text {eff }}$ and from wafer thickness $\mathrm{W}$ through $S_{\text {eff }, \text { max }}=\frac{W}{2_{\text {eff }}}$.

Those dielectrics layers were then applied to passivate the implanted emitters and Fig. 5 reports the corresponding $\mathrm{J}_{0 \mathrm{e}}$ values.

The most pronounced variation of $\mathrm{J}_{0 \mathrm{e}}$ as a function of surface passivation quality is observed at the highest anneal temperatures, due to the reduction of Auger and SRH recombination. Remarkably, the critical temperature at which Auger and SRH recombination becomes negligible compared to surface recombination (i.e., the temperature at which a variation of surface recombination velocity starts affecting $\mathrm{J}_{0 \mathrm{e}}$ ) is different for planar and bSi emitters. According to Figs. 5(a) and 5(b), a temperature $950^{\circ} \mathrm{C}$ or higher is required in bSi emitters to reduce Auger and SRH recombination, against $1050{ }^{\circ} \mathrm{C}$ in planar emitters.

Although Fig. 5(b) suggests a decisive effect of surface passivation after anneal at $1050{ }^{\circ} \mathrm{C}$, it remains limited to available experimental points. In addition, it does not allow separating Auger and surface mechanisms because SRH recombination also affects the results. Consequently, simulations are needed to extract fundamental surface recombination velocities and to comment on possible further improvement of emitter surface passivation.

\section{DISCUSSION ON THE PASSIVATION QUALITY AND EXTRACTION OF FUNDAMENTAL SURFACE RECOMBINATION VELOCITIES IN IMPLANTED b-Si EMITTERS}

The minority carrier surface recombination velocity $S_{n}$ $\left(\mathrm{p}+\right.$ emitters) or $\mathrm{S}_{\mathrm{p}}(\mathrm{n}+$ emitters) can be obtained from fits of the experimental lifetime and $\mathrm{J}_{\mathrm{Oe}}$ data using numerical simulations, e.g., with Sentarus or PC1D. ${ }^{23,36,43,46-50}$ The performance of textured emitters can be simulated in two dimensions, which thus allows using two-dimensional bSi doping profiles generated by a separate process simulator. ${ }^{48}$ However, we show that, implying some approximations in the bSi regions, useful insight on bSi emitter recombination mechanisms can be obtained using the PC1D freeware.

The simulations were performed with the updated PC1Dmod 6.2 software and were based on the most recent models mentioned in the corresponding publications by Haug et al. ${ }^{46,51}$ The simulation procedure is presented in detail in the supplementary material. In this section, the effect of implantation anneal temperature on surface recombination is analyzed qualitatively based on the extracted surface recombination velocities.

The $\mathrm{S}_{\mathrm{n}}$ values extracted from $\mathrm{Al}_{2} \mathrm{O}_{3}$-passivated emitters are shown in Fig. 6 as a function of implantation anneal temperature. The figure also displays literature results of planar emitters with a surface doping of approximately $2 \times 10^{19} \mathrm{~cm}^{-3}$, corresponding to the value obtained after anneal at $1050{ }^{\circ} \mathrm{C}$. In this work, the extracted $\mathrm{S}_{\mathrm{n}}$ or $\mathrm{J}_{0 \mathrm{e}}$ values were not rescaled by the area increase of the textured surfaces, contrarily to those reported in other studies. ${ }^{23,36}$

It has been shown that a reduction of boron surface concentration decreases surface recombination. ${ }^{41}$ Accordingly, the effect of anneal temperature on surface recombination is clearly visible in Fig. 6 . The decrease of surface doping caused by increased anneal temperature significantly reduces $\mathrm{S}_{\mathrm{n}}$ values in bSi emitters. The surface recombination velocity decreases from over $10^{6} \mathrm{~cm} / \mathrm{s}$ after anneal at $950^{\circ} \mathrm{C}$ or below to a value between $0 \mathrm{~cm} / \mathrm{s}$ and $10^{4} \mathrm{~cm} / \mathrm{s}$ at $1050{ }^{\circ} \mathrm{C}$, which corresponds to a $\mathbf{J}_{0 \mathrm{e}}$ of $20 \mathrm{fA} / \mathrm{cm}^{2}$ in $\mathrm{bSi}$. This suggests that
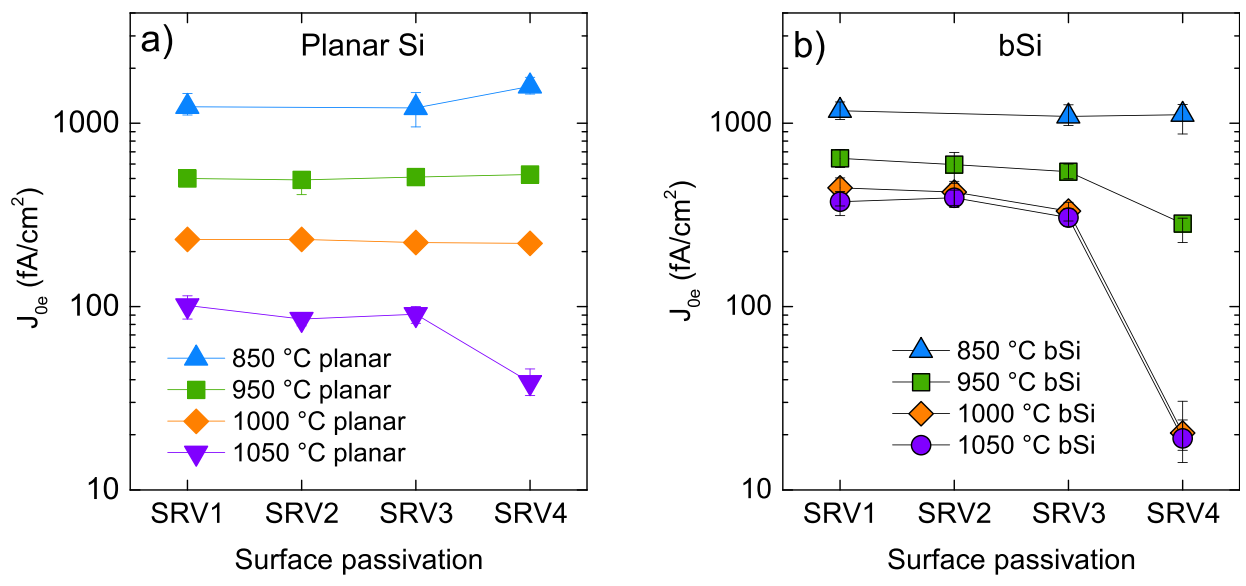

FIG. 5. Emitter saturation current in implanted emitters after anneal at different temperatures depending on the dielectric used in (a) planar samples and (b) black silicon. Error bars indicate uncertainty in $\mathrm{J}_{0 \mathrm{e}}$ extraction caused by injection-level-dependence. 


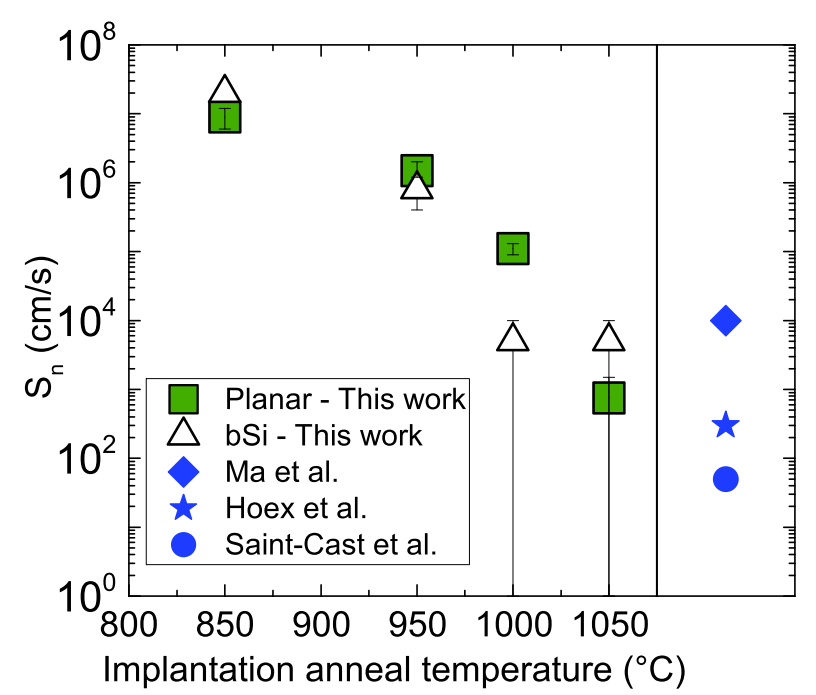

FIG. 6. Influence of implantation anneal temperature in implanted emitters passivated with annealed $\mathrm{Al}_{2} \mathrm{O}_{3}$ (SRV4 film) on fundamental surface recombination velocity $\mathrm{S}_{\mathrm{n}}$. The values were extracted with PC1D using doping profiles measured by ECV in the case of planar samples, and uniform profiles in the case of bSi. An effective dielectric charge corrected with surface area enhancement was used in bSi simulations. The right side of the graph displays literature results on planar surfaces with a surface doping of approximately $2 \times 10^{19} \mathrm{~cm}^{-3} \cdot 36,43,48$ The error bars indicate uncertainty in $\mathrm{J}_{0 \mathrm{e}}$ extraction caused by injection-level-dependence.

surface doping reduction also plays a major role in $\mathrm{J}_{0 \mathrm{e}}$ improvement in bSi implanted emitters. It should be noted that the large error margins reported at high anneal temperatures originate from fitting limitations. The $S_{n}$ in the planar emitter annealed at $1050^{\circ} \mathrm{C}$ cannot be determined accurately because values between 0 and $1500 \mathrm{~cm} / \mathrm{s}$ generate identical fits, as reported by Liao et al. and Ortega et al. ${ }^{47,50}$ The maximum value of $1500 \mathrm{~cm} / \mathrm{s}$ is however in good agreement, although somewhat higher, with the surface recombination values reported in the literature. Simulations of bSi emitters annealed at $1000^{\circ} \mathrm{C}$ and $1050^{\circ} \mathrm{C}$ involved the same limitation, explaining the large range of $\mathrm{S}_{\mathrm{n}}$ values obtained.

The uncertainty in $S_{n}$ observed above $1000{ }^{\circ} \mathrm{C}$ seems to be in fact limited by Auger recombination, although this is not clearly displayed in Fig. 6. This phenomenon appears more clearly in Fig. 7, presenting the simulated variation of $\mathrm{J}_{0 \mathrm{e}}$ as a function of $\mathrm{S}_{\mathrm{n}}$ in planar and bSi emitters. The emitters were annealed at $1050^{\circ} \mathrm{C}$ and passivated with annealed $\mathrm{Al}_{2} \mathrm{O}_{3}$ (SRV4 film). The saturation of $\mathrm{J}_{0 \mathrm{e}}$ in bSi emitters at low $\mathrm{S}_{\mathrm{n}}$ [Fig. 7(b)] indicates that, at $1050^{\circ} \mathrm{C}$, a further reduction of fundamental surface recombination velocity has virtually no effect on the $\mathrm{J}_{0 \mathrm{e}}$ values. This result suggests that recombination in bSi emitters is dominated by the Auger mechanism at this temperature. A similar observation can be made in bSi emitters annealed at $1000{ }^{\circ} \mathrm{C}$. On the other hand, the inset in Fig. 7(b) shows that the point SRV4 is not yet in the saturation regime after anneal at $950{ }^{\circ} \mathrm{C}$. In this case, it indicates that $\mathrm{J}_{0 \mathrm{e}}$ could be further reduced by improving surface passivation.

In summary, increasing anneal temperature from $850{ }^{\circ} \mathrm{C}$ to $1000{ }^{\circ} \mathrm{C}$ significantly reduces surface recombination, suggesting a decrease in surface doping. Auger recombination dominates after anneals at $1000^{\circ} \mathrm{C}$ and $1050{ }^{\circ} \mathrm{C}$; thus, no further improvement of surface passivation beyond annealed $\mathrm{Al}_{2} \mathrm{O}_{3}$ quality could improve $\mathrm{J}_{0 \mathrm{e}}$.

\section{CONCLUSION}

We discussed the advantages of ion implantation for bSi emitter formation and compared it with the more commonly used diffusion process. By nature, ion implantation prevents the increased Auger recombination observed in diffused emitters, which is caused by excessive doping through the sides of the nanostructures. An emitter saturation current $\left(\mathrm{J}_{\mathrm{Oe}}\right)$ as low as $20 \mathrm{fA} / \mathrm{cm}^{2}$ was measured in an implanted bSi emitter passivated by annealed $\mathrm{Al}_{2} \mathrm{O}_{3}$ for a $\mathrm{R}_{\mathrm{sh}}$ of $170 \Omega / \mathrm{sq}$, which demonstrates the potential of this technique for nanostructure doping. The possibility to control surface doping via implantation anneal parameters represents a significant advantage over emitter diffusion, as it implies that $\mathrm{J}_{0 \mathrm{e}}$ can be improved without modification of the bSi morphology or of the sheet resistance. In addition, low reflectance was preserved after implantation and high temperature treatments.
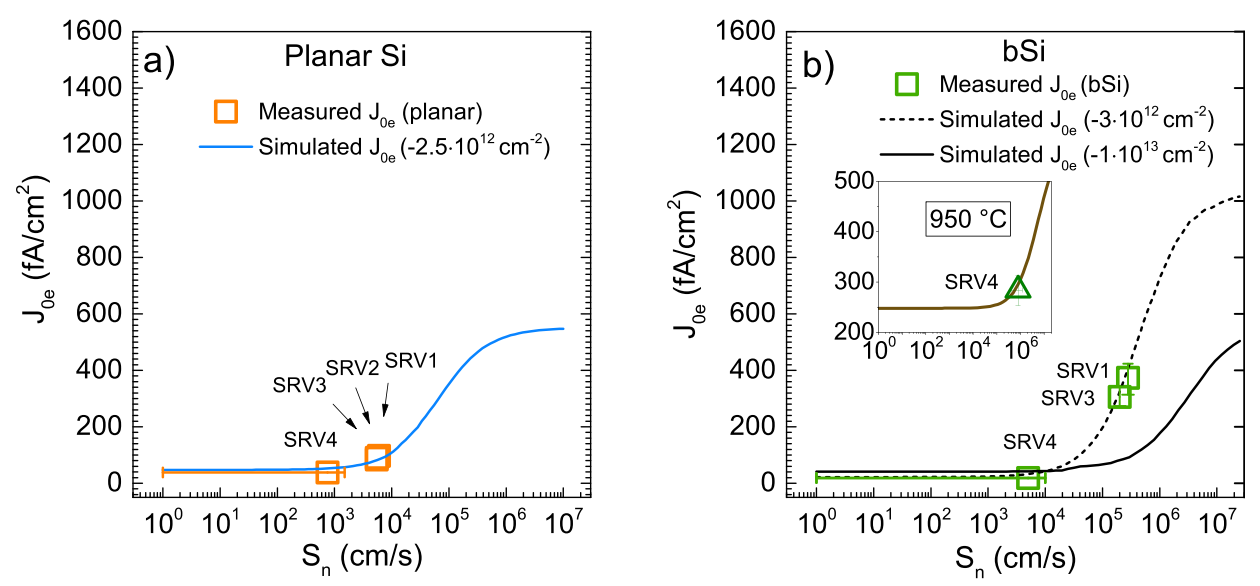

FIG. 7. Experimental and simulated $\mathrm{J}_{0 \mathrm{e}}$ values as a function of $\mathrm{S}_{\mathrm{n}}$ for different passivation layers after implantation anneal at $1050{ }^{\circ} \mathrm{C}$ (and $950{ }^{\circ} \mathrm{C}$ in the inset). The lines represent $\mathrm{J}_{0 \mathrm{e}}$ simulation results on (a) planar emitters with ECV doping profiles and (b) bSi emitters with uniform doping profiles. The symbols represent the experimental points corresponding to the passivation films SRV1,2,3,4 listed in Table II, which were fitted with the help of PC1D simulations to obtain $\mathrm{S}_{\mathrm{n}}$ values. The error bars indicate fitting uncertainty. The values in brackets indicate the fixed charge densities used in the simulations. 
In addition, we separated the different recombination mechanisms in implanted bSi emitters and discussed the contribution of bulk and surface recombination to the overall emitter recombination. The implantation anneal temperature required to significantly reduce bulk emitter recombination was found to be lower in bSi than in planar emitters. Relatively low electron surface recombination velocities were found in bSi emitters despite the high surface area and were reduced by increasing anneal temperature. The simulations also indicated that, beyond $1000^{\circ} \mathrm{C}$, bSi doping was sufficiently reduced so that $\mathrm{J}_{0 \mathrm{e}}$ was not anymore limited by surface recombination. The results reported here open opportunities for implantation on bSi and allow relatively simple processing of selective bSi emitters.

\section{SUPPLEMENTARY MATERIAL}

See supplementary material for a detailed description of the simulation procedure.

\section{ACKNOWLEDGMENTS}

This research was undertaken at the Micronova Nanofabrication Centre of Aalto University and in the cleanroom laboratory of the Micro and Nanotechnologies group at the Universitat Politècnica de Catalunya (UPC), Barcelona. This work was supported by the Spanish Ministry of Economy and Competitiveness MINECO (PCIN-2014-055) and Finnish TEKES (40329/14) agencies under Solar-Era.Net FP7 European Network. The work was also funded by the Energy Efficiency Research Program of Aalto University School of Electrical Engineering (Effinano Project No. 91581015), the doctoral school of Aalto School of Electrical Engineering, and the Project No. ENE2013-49984-EXP of the Spanish Ministry of Economy and Competitiveness (MINECO). The authors would like to thank Achim Kimmerle for providing help with the $\mathrm{J}_{0 \mathrm{e}}$ corrections.

${ }^{1}$ R. B. Stephens and G. D. Cody, Thin Solid Films 45(1), 19 (1977).

${ }^{2}$ T. K. Chong, K. J. Weber, K. M. Booker, and A. W. Blakers, IEEE J. Photovoltaics 4(5), 1235 (2014).

${ }^{3}$ M. Otto, M. Kroll, T. Käsebier, R. Salzer, A. Tünnermann, and R. B. Wehrspohn, Appl. Phys. Lett. 100(19), 191603 (2012).

${ }^{4}$ P. Repo, A. Haarahiltunen, L. Sainiemi, M. Yli-Koski, H. Talvitie, M. C. Schubert, and H. Savin, IEEE J. Photovoltaics 3(1), 90 (2013).

${ }^{5}$ G. von Gastrow, R. Alcubilla, P. Ortega, M. Yli-Koski, S. Conesa-Boj, A. F. i Morral, and H. Savin, Sol. Energy Mater. Sol. Cells 142, 29 (2015).

${ }^{6}$ S. Zhong, B. Liu, Y. Xia, J. Liu, J. Liu, Z. Shen, Z. Xu, and C. Li, Sol. Energy Mater. Sol. Cells 108, 200 (2013).

${ }^{7}$ Z. Shen, B. Liu, Y. Xia, J. Liu, J. Liu, S. Zhong, and C. Li, Scr. Mater. 68(3-4), 199 (2013).

${ }^{8}$ Y. Wang, Y. P. Liu, T. Lai, H. L. Liang, Z. L. Li, Z. X. Mei, F. M. Zhang, A. Kuznetsov, and X. L. Du, RSC Adv. 3(35), 15483 (2013).

${ }^{9}$ S. Zhong, Z. Huang, X. Lin, Y. Zeng, Y. Ma, and W. Shen, Adv. Mater. 27(3), 555 (2015).

${ }^{10}$ B. Kafle, J. Schön, C. Fleischmann, S. Werner, A. Wolf, L. Clochard, E. Duffy, M. Hofmann, and J. Rentsch, Sol. Energy Mater. Sol. Cells 152, 94 (2016).

${ }^{11}$ W. Wang, M. Tsai, J. Yang, C. Hsu, and M. Chen, ACS Appl. Mater. Interfaces 7(19), 10228 (2015).

${ }^{12}$ P. Repo, J. Benick, G. von Gastrow, V. Vähänissi, F. D. Heinz, J. Schön, M. C. Schubert, and H. Savin, Phys. Status Solidi RRL 7(11), 950 (2013).

${ }^{13} \mathrm{P}$. Repo, J. Benick, V. Vähänissi, J. Schön, G. von Gastrow, B. Steinhauser, M. C. Schubert, M. Hermle, and H. Savin, Energy Proc. 38, 866 (2013).
${ }^{14}$ F. Toor, J. Oh, and H. M. Branz, Prog. Photovoltaics Res. Appl. 23(10), 1375 (2015).

${ }^{15}$ Y. Xia, B. Liu, J. Liu, Z. Shen, and C. Li, Sol. Energy 85(7), 1574 (2011).

${ }^{16}$ H. Yuan, V. E. Yost, M. R. Page, P. Stradins, D. L. Meier, and H. M. Branz, Appl. Phys. Lett. 95(12), 123501 (2009).

${ }^{17}$ S. Wang, Q. Li, K. Tao, R. Jia, S. Jiang, D. Wang, and H. Dong, J. Mater. Sci.: Mater. Electron. 27(5), 4378 (2016).

${ }^{18}$ X. Liu, P. R. Coxon, M. Peters, B. Hoex, J. M. Cole, and D. J. Fray, Energy Environ. Sci. 7, 3223 (2014).

${ }^{19}$ J. Oh, H. Yuan, and H. M. Branz, Nat. Nanotechnol. 7(11), 743 (2012).

${ }^{20}$ G. Dingemans and W. M. M. Kessels, J. Vac. Sci. Technol. A 30(4), 040802 (2012).

${ }^{21}$ T. Kubo, J. J. Freedsman, Y. Iwata, and T. Egawa, Semicond. Sci. Technol. 29(4), 045004 (2014).

${ }^{22}$ A. Ingenito, O. Isabella, and M. Zeman, Sol. Energy Mater. Sol. Cells 157, 354 (2016).

${ }^{23}$ A. Kimmerle, M. Momtazur Rahman, S. Werner, S. Mack, A. Wolf, A. Richter, and H. Haug, J. Appl. Phys. 119(2), 025706 (2016).

${ }^{24}$ J. Benick, N. Bateman, and M. Hermle, in Proceedings of the 25th European Photovoltaic Solar Energy Conference, Valencia, Spain (2010), p. 1169.

${ }^{25}$ C. E. Dubé, B. Tsefrekas, D. Buzby, R. Tavares, W. Zhang, A. Gupta, R. J. Low, W. Skinner, and J. Mullin, Energy Proc. 8, 706 (2011).

${ }^{26}$ H. Hieslmair, L. Mandrell, I. Latchford, M. Chun, J. Sullivan, and B. Adibi, Energy Proc. 27, 122 (2012).

${ }^{27}$ R. Müller, J. Benick, N. Bateman, J. Schön, C. Reichel, A. Richter, M. Hermle, and S. W. Glunz, Sol. Energy Mater. Sol. Cells 120(Part A), 431 (2014).

${ }^{28}$ E. Rimini, Ion Implantation: Basics to Device Fabrication (Springer Science and Business Media, 2013).

${ }^{29}$ J. Krügener, E. Bugiel, R. Peibst, F. Kiefer, T. Ohrdes, R. Brendel, and H. J. Osten, Semicond. Sci. Technol. 29(9), 095004 (2014).

${ }^{30}$ G. von Gastrow, S. Li, M. Putkonen, M. Laitinen, T. Sajavaara, and H. Savin, Appl. Surf. Sci. 357(Part B), 2402 (2015).

${ }^{31}$ D. K. Schroder, Mater. Sci. Eng. B 91-92, 196 (2002).

${ }^{32}$ D. K. Schroder, Semiconductor Material and Device Characterization (John Wiley and Sons, 2006).

${ }^{33}$ R. A. Sinton and A. Cuevas, Appl. Phys. Lett. 69(17), 2510 (1996).

${ }^{34} \mathrm{D}$. Kane and R. Swanson, in Proceedings of the IEEE Photovoltaic Specialists Conference (1985), Vol. 18, pp. 578-583.

${ }^{35}$ A. Blum, J. Swirhun, R. Sinton, and A. Kimmerle, in Proceedings of the 28th European Photovoltaic Solar Energy Conference and Exhibition, Paris, France (2013), pp. 1521-1523.

${ }^{36}$ P. Saint-Cast, A. Richter, E. Billot, M. Hofmann, J. Benick, J. Rentsch, R. Preu, and S. W. Glunz, Thin Solid Films 522, 336 (2012).

${ }^{37}$ A. Richter, S. W. Glunz, F. Werner, J. Schmidt, and A. Cuevas, Phys. Rev. B 86(16), 165202 (2012).

${ }^{38}$ A. Schenk, J. Appl. Phys. 84(7), 3684 (1998).

${ }^{39}$ A. Kimmerle, J. Greulich, and A. Wolf, Sol. Energy Mater. Sol. Cells 142, 116 (2015).

${ }^{40}$ D. Caughey and R. Thomas, Proc. IEEE 55(12), 2192 (1967).

${ }^{41}$ A. Cuevas, M. Stuckings, J. Lau, and M. Petravic, in Proceedings of the 14th European Photovoltaic Solar Energy Conference (WIP Renewable Energies Barcelona, Spain, 1997), pp. 2416-2419.

${ }^{42}$ P. Pichler, ICECREM version 4.3, FhG-AIS Erlangen, 1996.

${ }^{43}$ B. Hoex, J. Schmidt, R. Bock, P. P. Altermatt, M. C. M. van de Sanden, and W. M. M. Kessels, Appl. Phys. Lett. 91, 112107 (2007).

${ }^{44}$ J. Benick, B. Hoex, M. C. M. van de Sanden, W. M. M. Kessels, O. Schultz, and S. W. Glunz, Appl. Phys. Lett. 92, 253504 (2008).

${ }^{45}$ J. Schön, A. Abdollahinia, R. Müller, J. Benick, M. Hermle, W. Warta, and M. C. Schubert, Energy Proc. 38, 312 (2013).

${ }^{46}$ H. Haug, J. Greulich, A. Kimmerle, and E. S. Marstein, Sol. Energy Mater. Sol. Cells 142, 47 (2015).

${ }^{47}$ B. Liao, R. Stangl, F. Ma, Z. Hameiri, T. Mueller, D. Chi, A. G. Aberle, C. S. Bhatia, and B. Hoex, J. Appl. Phys. 114, 094505 (2013).

${ }^{48}$ F. Ma, S. Duttagupta, M. Peters, G. S. Samudra, A. G. Aberle, and B. Hoex, Energy Proc. 38, 124 (2013).

${ }^{49}$ B. Min, H. Wagner, A. Dastgheib-Shirazi, A. Kimmerle, H. Kurz, and P. P. Altermatt, Phys. Status Solidi RRL 8(8), 680 (2014).

${ }^{50} \mathrm{P}$. Ortega, M. Vetter, S. Bermejo, and R. Alcubilla, Semicond. Sci. Technol. 23(12), 125032 (2008).

${ }^{51}$ H. Haug and J. Greulich, Energy Proc. 92, 60 (2016). 